\title{
Experimental and Numerical Study on Supersonic Ejectors Working with R-1234ze(E)
}

\author{
Jan Kracik ${ }^{1, *}$, Vaclav Dvorak ${ }^{1}, V u$ Nguyen $\operatorname{Van}^{1}$ and Kamil Smierciew ${ }^{2}$ \\ ${ }^{1}$ Department of Power Engineering Equipment, Faculty of Mechanical Engineering, Technical University of Liberec, Studentska 2, \\ 46117, Liberec, the Czech Republic \\ ${ }^{2}$ Department of Heating and Cooling Technics, the Faculty of Mechanical Engineering, Bialystok University of Technology, ul. Wiejska \\ 45C, 15-351 Bialystok, Poland
}

\begin{abstract}
These days, much effort is being put into lowering the consumption of electric energy and involving renewable energy sources. Many engineers and designers are trying to develop environment-friendly technologies worldwide. It is related to incorporating appropriate devices into such technologies. The object of this paper is to investigate these devices in connection with refrigeration systems. Ejectors can be considered such as these devices. The primary interest of this paper is to investigate the suitability of a numerical model for an ejector, which is incorporated into a refrigeration system. In the present paper, there have been investigated seven different test runs of working of the ejector with a working fluid R-1234ze(E). Some of the investigated cases seem to have a good agreement and there are no significant discrepancies between them, however, there are also cases that do not correspond to the experimental data at all. The ejector has been investigated in both on-design and off-design working modes. A comparison between the experimental and numerical data (CFD) performed by Ansys Fluent software is presented and discussed for both an ideal and a real gas model. In addition, an enhanced analytical model has been introduced for all runs of the ejector.
\end{abstract}

\section{Introduction}

Ejectors are devices which are able to utilize low-grade thermal energy to drive refrigeration systems and therefore reduce consumption of electric energy which is otherwise needed for working of a refrigeration system with a compressor. Refrigeration system has been probably one of the most common applications of ejectors in recent years. In addition, ejectors are relatively easy to manufacture and compared to, for example, sorption systems require lower investment costs. Ejectors are commonly used for their simple design, reliability and lack of moving parts. Probably the main problem that prevents ejectors from being used more is their low efficiency which does not exceed 30 percent. There has been done much work on investigation of ejectors so far. However, there are still many unexplored areas concerning ejectors that require more research efforts and a rigorous investigation. It should be noted that the flow and especially the mixing of flows in ejector are very difficult to analyse.

As previously mentioned, an ejector is a substitution of a compressor in a classic vapour compression system. The compression of the secondary fluid flowing from the evaporator, which would be otherwise performed by a compressor, is achieved by compressing the fluid in the ejector and then it is further discharged to the condenser [1].

There are two major types of mixing in ejector according to work by Keenan and Neumann [2] distinguished: the constant-area mixing and the constantpressure mixing. The design of constant-pressure ejectors is rather complex and causes lots of problems for researchers due to its very strict requirements on a precise determination of mixing chamber wall shape to ensure that the static pressure remains constant throughout the whole mixing chamber. Ejectors designed based on constant-pressure mixing should give higher performance in most cases. However, there has not been established a definite link between the performance of constant area and constant pressure ejectors [3]. The flow in constant-pressure ejectors was for example investigated by Kracik and Dvorak in work [4].

A commonly used ejector refrigeration system can be seen in Fig. 1. In this case, the motive vapour is generated in generator and the heat for its heating is usually a low-grade heat, i.e. the heat is extracted from a low-temperature heat source. The possibility of using a source with a relatively low temperature seems to make ejectors so interesting and remarkable.

The refrigeration system has already been investigated in more detail by Smierciew et al. in work [1]. However, in that work the system was investigated

\footnotetext{
* Corresponding author: jan.kracik@tul.cz
} 
for isobutane as a working fluid. Isobutane is classified as explosive, therefore, it is not suitable for some applications. The same author also investigated an ejector system with $\mathrm{R}-1234 \mathrm{ze}(\mathrm{E})$ as a refrigerant [5]; however, in this case, the ejector geometry was slightly different. Fig. 2 illustrates the ejector geometry used in the present paper.

This paper presents an ejector operating with R$1234 \mathrm{ze}(\mathrm{E})$, which is considered as a safe alternative to isobutane (R-600a). According to Smierciew et al. [5] there are no research studies dealing with either experimental or numerical investigation on ejectors operating with R-1234ze(E) at this scale. Furthermore, this paper attempts to present both experimental and numerical results accompanied by a theoretical method of ejector performance calculation and show dissimilarities and discrepancies between the different numerical modelling approaches.

Each ejector works under specific conditions and three main modes of ejector performance are distinguished. These modes are obvious from Fig. 3. It can be seen that they divide the performance line of a supersonic ejector into three sections depending on the value of the condenser pressure or back-pressure as shown in the figure. It is highly desirable to design supersonic ejectors for working in the on-design region. This region is recognised as a part with a maximal entrainment ratio and it is also a sign that both the primary and secondary flow are choked, i.e. double choking region. There is no dependency of entrainment ratio or secondary mass flow rate on the condenser pressure in this region. The region should be as wide as possible so that an ejector could sustain its maximal entrainment ratio within a wide range of condenser pressures. The second region is often denoted as the offdesign region. In this case, there is a strong dependency of entrainment ratio on the condenser pressure. The secondary mass flow rate and the back-pressure are closely coupled, therefore, the ejector performance is highly sensitive to the adjusted parameters and the secondary flow is not choked anymore. The pressure which separates these two regions is called the critical pressure and the point corresponding to this pressure is the critical point. The location of the critical point on the performance line depends on a given ejector geometry and given parameters on the inlets of ejector. The last region is the region of reverse flow, i.e. an ejector is not able to entrain any fluid from the evaporator and stops working properly. It should be noted that it is always desirable to avoid working ejectors under these conditions.

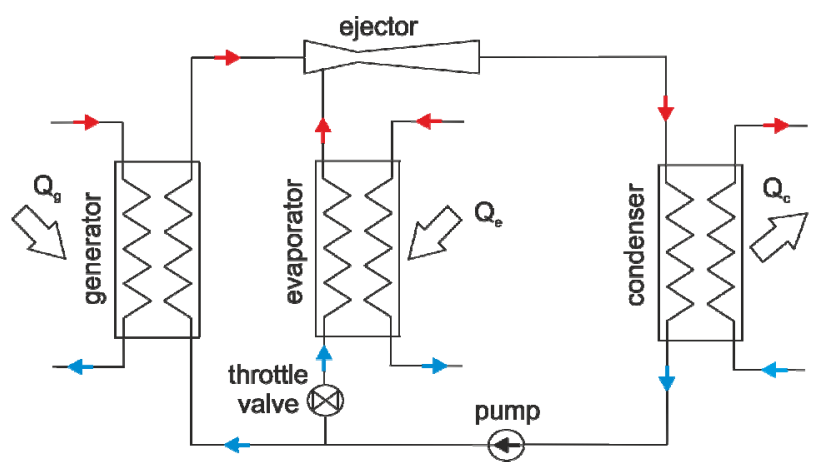

Fig. 1. Schematic diagram of a common ejector refrigeration system.

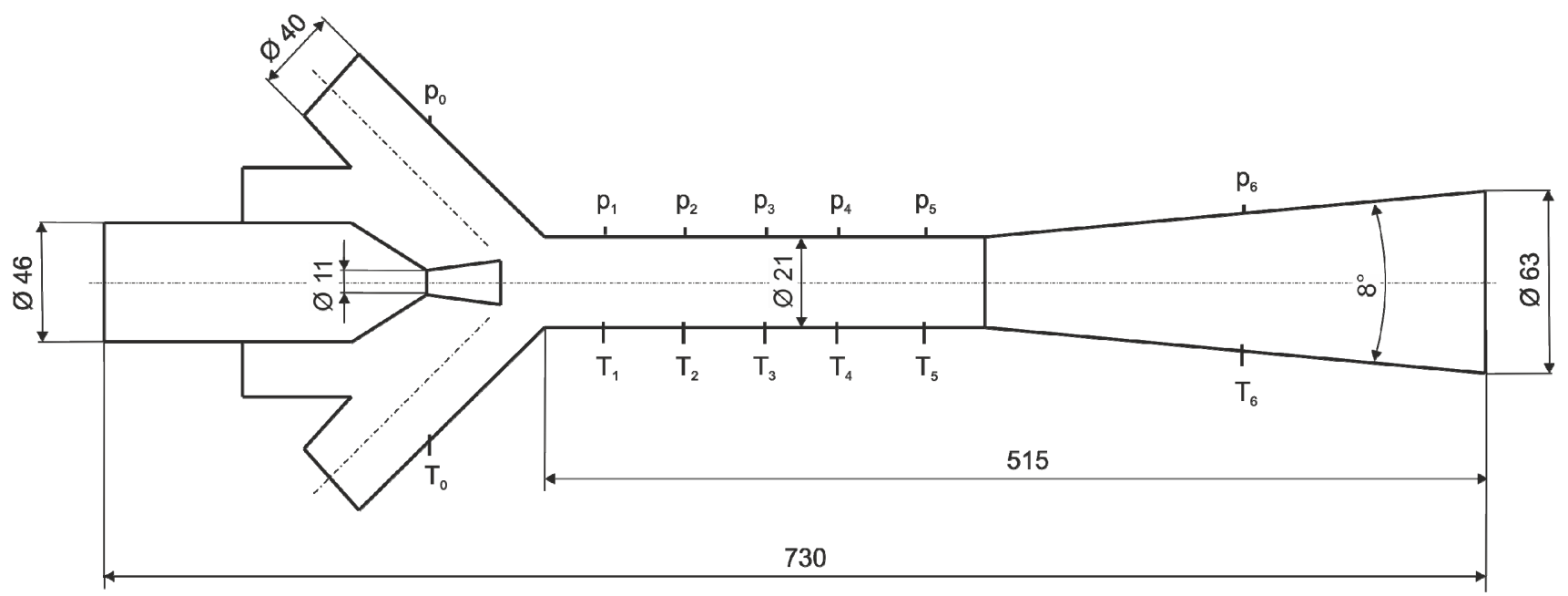

Fig. 2. Ejector geometry with main dimensions in millimetres. 


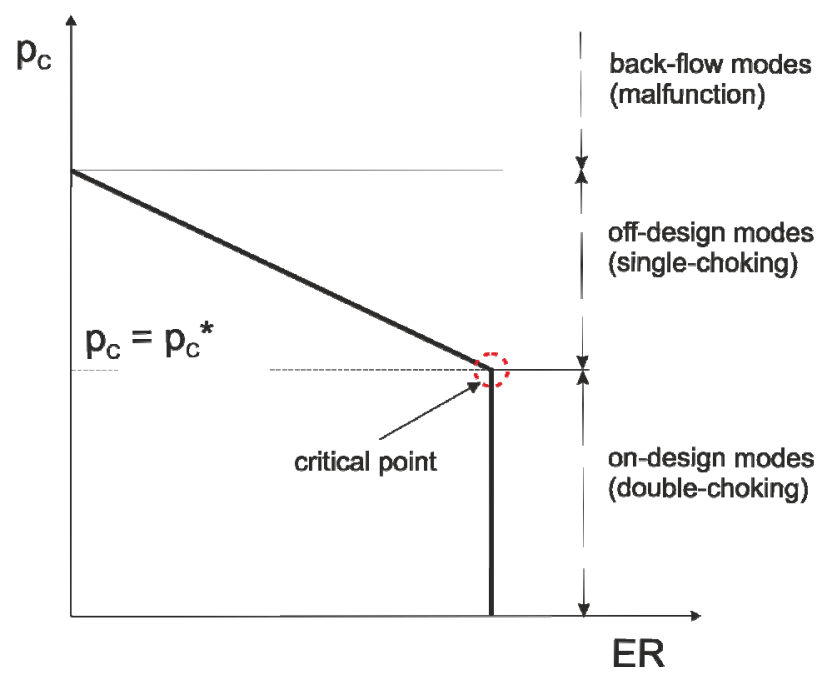

Fig. 3. Typical performance line of supersonic ejectors.

\section{Methods and experimental installation}

Performance of any ejector can be described by two major parameters. The first parameter is the entrainment ratio that is defined as

$$
E R=\frac{\dot{m}_{e}}{\dot{m}_{g}},
$$

where $\dot{m}$ is mass flow rate and indices $e$ and $g$ stand for evaporator and generator, respectively. The other parameter is the compression ratio and can be calculated as

$$
C R=\frac{p_{c}-p_{e}}{p_{g}-p_{e}}
$$

where $p$ is the absolute pressure and index $c$ stands for condenser.

The experimental apparatus is presented in Fig. 4 and 5. The apparatus was built at the Bialystok University of Technology in Bialystok, Poland. The main components of the apparatus are listed in the figure legend. The ejector itself was equipped with a pair of temperature and pressure sensors in the suction chamber, five pairs of sensors in the mixing chamber and a pair of sensors in the diffuser (see Fig. 2). The throat diameter of the motive nozzle was $11 \mathrm{~mm}$. The location of the temperature sensors (RTD) and pressure sensors (P) on the experimental apparatus is obvious from Fig. 4. Accuracy of the sensors were as follows: $0.25 \%$ for the pressure sensors, $0.20 \%$ for the temperature sensors, and $0.15 \%$ for the Coriolis mass flow meters. The measurement error was calculated by means of the total derivative approach. All of the measurement sensors and the entire measurement system were calibrated before each experimental run.

Three auxiliary loops were applied in the experimental apparatus that serve for thermal load of the evaporator, for condenser cooling, and as a heat source for the vapour generator. The Coriolis mass flow meters and temperature sensors at the heat exchangers inlets and outlets were installed on these loops. The auxiliary loops allowed to adjust the operation parameters in a wide range of thermal capacity. Water was used as a working fluid in the generator heat source system and ethylene glycol was used as a heat transfer fluid in the evaporator heat load system and in the condenser cooling system. A dry cooler is used in the condenser cooling system.

The presented system is proposed for operation with a district heating system, which is considered as the lowgrade motive source. During experiments, operation of the district heating system was simulated by the electric heater system of thermal capacity approximately 100 $\mathrm{kW}$. The electric heater operated at its full capacity. The mass flow rate of the circulating water in the heating loop was set to maintain its temperature at the vapour generator inlet below $70{ }^{\circ} \mathrm{C}$. The pressure and the temperature of the motive vapour at the ejector inlet were controlled by control valves. Moreover, a regenerative heat exchanger was applied for improvement of the effectiveness of the ejection device.

A diaphragm pump was used for the circulation of the refrigerant. The pump is driven by motor power of 3 $\mathrm{kW}$ achieved at $700 \mathrm{RPM}$. In general, the pump is used for circulation of part of the refrigerant. In other words, the pump feeds only the vapour generator. However, as it can be seen in Fig. 4, the system pump is located right behind the condenser before the mixed fluid is divided into the motive and the entrained fluid. It means that the pump draws all the amount of the refrigerant, and consequently the pump consumes more energy. However, location of the pump in the presented system enables more precise and easier regulation and control of the system operation. In refrigeration system operating with commonly used refrigerants like R-404A or R-134a the throttle valve that feeds the evaporator operates at a pressure difference between the condenser and the evaporator of $500 \mathrm{kPa}$ or more. For low-pressure refrigerants this pressure difference is between $200 \mathrm{kPa}$ and $300 \mathrm{kPa}$. Without the initial increase in pressure in the throttle valve, the operation would be less stable and unpredictable. This is the reason for the location of the pump. However, since the liquid pump consumes almost negligible amount of energy in the total motive power consumption of the system, the current system configuration does not lead to significant deterioration of COP and provides easier control of the operation.

The measurement system was based on two National Instrument systems. The computer used LabVIEW software which is capable to receive on-line data from the refrigeration properties software REFPROP $[6,7]$. The sampling frequency during measurement was $1 \mathrm{~Hz}$. The measurement time was between 90 - 120 seconds. All readings were averaged to form one experimental point. The operating conditions were considered as stable when the pressure and temperature profiles did not show significant changes. Table 1 illustrates the investigated runs with the operating conditions. 


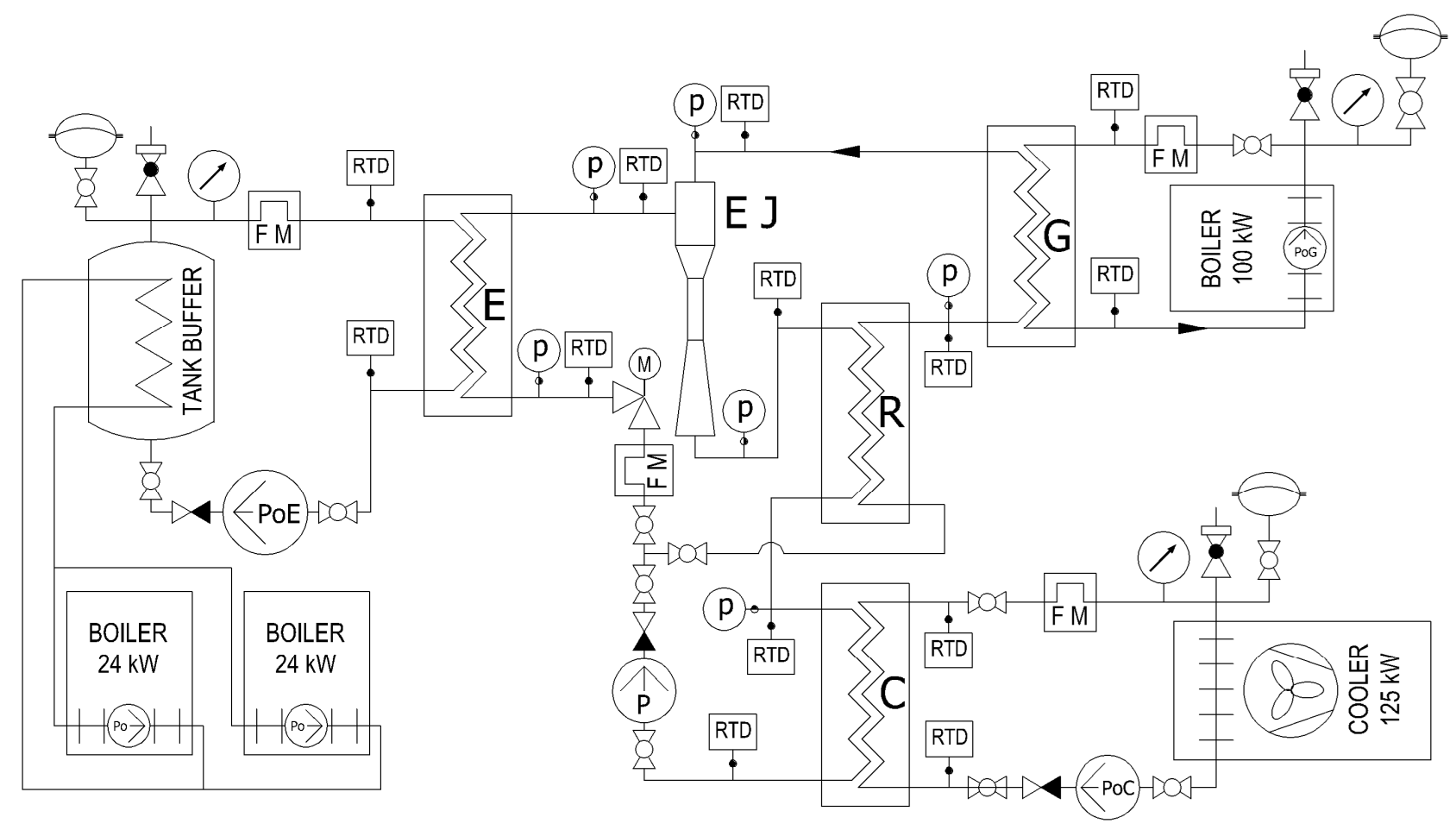

Fig. 4. Schematic diagram of the experimental apparatus: vapour generator $(G)$, condenser $(C)$, evaporator (E), ejector (EJ), pump $(\mathrm{P})$, internal heat exchanger (R), M - throttle valve, RTD - temperature sensor, $\mathrm{p}$ - pressure sensor, FM - flow meter.

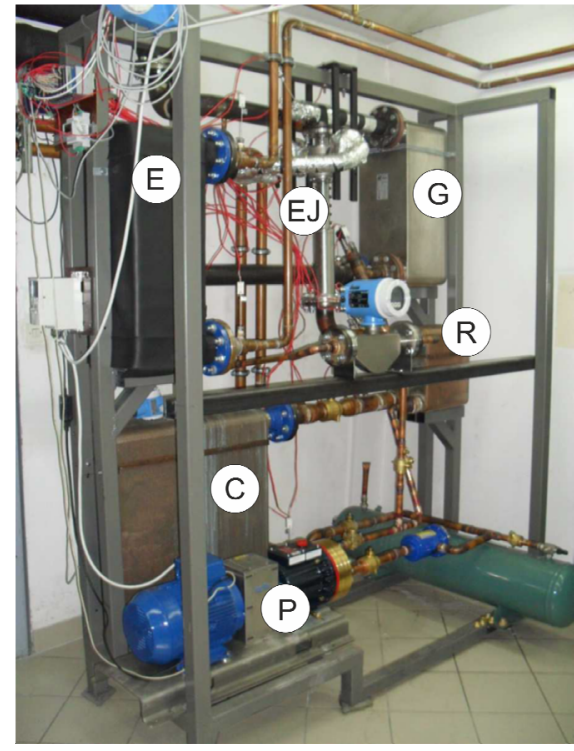

Fig. 5. Photo of the experimental apparatus.

Table 1. Ejector operating conditions.

\begin{tabular}{lccccc}
\hline & $\begin{array}{c}\mathrm{p}_{\mathrm{g}} \\
(\mathrm{MPa})\end{array}$ & $\begin{array}{c}\mathrm{p}_{\mathrm{e}} \\
(\mathrm{MPa})\end{array}$ & $\begin{array}{c}\mathrm{p}_{\mathrm{c}} \\
(\mathrm{MPa})\end{array}$ & $\begin{array}{c}\mathrm{T}_{\mathrm{g}} \\
(\mathrm{K})\end{array}$ & $\begin{array}{c}\mathrm{T}_{\mathrm{e}} \\
(\mathrm{K})\end{array}$ \\
\hline run no. 1 & 1.174 & 0.216 & 0.420 & 338.3 & 278.9 \\
run no. 2 & 1.180 & 0.210 & 0.479 & 335.1 & 284.0 \\
run no. 3 & 1.170 & 0.203 & 0.503 & 335.5 & 281.8 \\
run no. 4 & 1.165 & 0.207 & 0.509 & 337.2 & 279.5 \\
run no. 5 & 1.179 & 0.256 & 0.541 & 338.1 & 283.4 \\
run no. 6 & 1.182 & 0.265 & 0.552 & 338.2 & 284.1 \\
run no. 7 & 1.205 & 0.320 & 0.612 & 341.7 & 284.9 \\
\hline
\end{tabular}

\section{Numerical modelling}

Since this paper aims at assessment the ability of numerical methods (CFD) for calculation of the flow in supersonic ejectors, especially in refrigeration applications, this part is crucial. The most important issue is probably to be able to obtain plausible results in a wide range of operation of the ejector. In other words, it is highly desirable to obtain such a numerical solution which is very close to the experimental results in the different modes of supersonic ejector operation, from the on-design mode through the off-design mode to the back-flow mode (malfunction).

It should be noted that there have been done many studies for air as a working fluid comparing CFD with experiments. The results seem to be in a good agreement in the on-design mode, however, the further from the critical point towards the back-flow regimes an ejector working regime is the larger discrepancy between CFD and experiment is often recognized.

In order to reduce the complexity of the numerical model, one quarter of a three-dimensional model of the ejector was used for all calculations (Fig. 6).

The flow in the ejector is described by the compressible form of the conservation equations since they have proved to be more suitable for describing compressible flows with significant density changes. The influence of thermodynamic and transport properties of the used refrigerant are not assumed to be significant, therefore, these properties are considered as constants during the simulations. The working fluid was modelled according to both the ideal and the real gas model. 


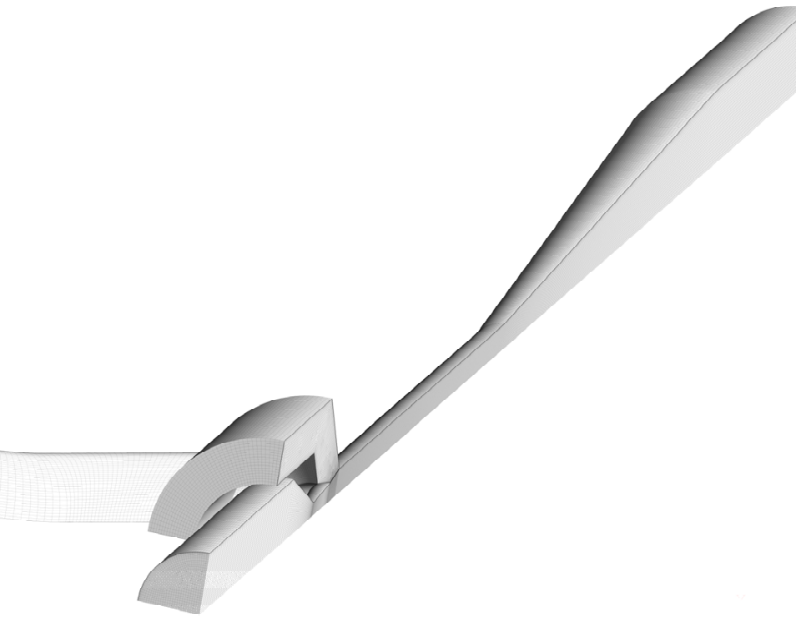

Fig. 6. The numerical model of the ejector.

The ideal gas was modelled with the following properties: specific heat $c_{p}=291.74 \mathrm{~J} \cdot \mathrm{kg}^{-1} \cdot \mathrm{K}^{-1}$, thermal conductivity $k=1.36 \cdot 10^{-2} \mathrm{~W} \cdot \mathrm{m}^{-1} \cdot \mathrm{K}^{-1}$, viscosity $\mu=1.224 \cdot 10^{-5} \mathrm{~Pa} \cdot \mathrm{s}$ and molecular weight $M=114 \mathrm{~kg} \cdot \mathrm{kmol}^{-1}$.

As regards the other modelling approach, the real gas was modelled using the NIST REFPROP database provided by Ansys Fluent Inc. The main limitation of this approach is that it assumes that the fluid used in the ANSYS Fluent calculation is superheated vapour, supercritical fluid, or liquid. It should be noted that subcritical flow conditions, where vapour coexists with liquid in two-phase flow, are not supported.

The flow governing equations are written in the form as follows:

$$
\begin{gathered}
\frac{\partial \rho}{\partial t}+\frac{\partial}{\partial x_{i}}\left(\rho u_{i}\right)=0 \\
\frac{\partial}{\partial t}\left(\rho u_{i}\right)+\frac{\partial}{\partial x_{j}}\left(\rho u_{i} u_{j}\right)=-\frac{\partial}{\partial x_{j}}\left(p \delta_{i j}\right)+\frac{\partial \tau_{i j}}{\partial x_{j}} \\
\frac{\partial}{\partial t}\left(\rho e_{0}\right)+\frac{\partial}{\partial x_{j}}\left(\rho u_{j} e_{0}+u_{j} p+q_{j}-u_{i} \tau_{i j}\right)=0, \\
p=\rho r T
\end{gathered}
$$

and for a Newtonian fluid the viscous stress term can be written in form

$$
\tau_{i j}=\mu_{e f f}\left(\frac{\partial u_{i}}{\partial x_{j}}+\frac{\partial u_{j}}{\partial x_{i}}\right)-\frac{2}{3} \mu_{e f f} \frac{\partial u_{k}}{\partial x_{k}} \delta_{i j} .
$$

The governing equations are solved using the commercial CFD package Fluent provided by Ansys, Inc. Three-dimensional hexahedral mesh with nearly $1,700,000$ elements was created for calculations. The ejector mesh is illustrated in more detail in Fig. 7. The $\mathrm{y}+$ was in most of the cases below value 5. Double precision option was used to get more precise solution. For all variables the second-order upwind scheme was utilized. As already mentioned, all the thermodynamics and transport properties as well as boundary conditions are held constant during the simulations.

Although the use of the transient term in the governing equations seems to be beneficial since this term, in some cases, is able to stabilize the solution during the calculation, the steady state governing equations were used for the calculations with the real gas, and in these cases the transient term was omitted. The reason for doing it in this way was that it appeared almost impossible to achieve convergence in a transient way when using the real gas model. On the other hand, all calculations with the ideal gas model were performed in a transient manner.

To take turbulence effects into account the k- $\omega$ SST turbulence model, which has been proved to be the most suitable for ejectors calculations [8], was used. However, most of the calculations for validating suitability of a proper turbulence model have been done for air as a working fluid. The proper choice of the most suitable turbulence model for calculating flows with a different fluid than the air could be an issue and may require more attention in future works as each refrigerant may require its own CFD study on the most suitable turbulence model. Nevertheless, it is believed that for the current calculations the most suitable turbulence model for air ejectors is also the most suitable turbulence model for any other working fluid. Furthermore, it is worth to mention that unlike the air under a wide range of conditions, most refrigerants behave like a real gas. For more information on this topic, see Ansys Fluent documentation [9].

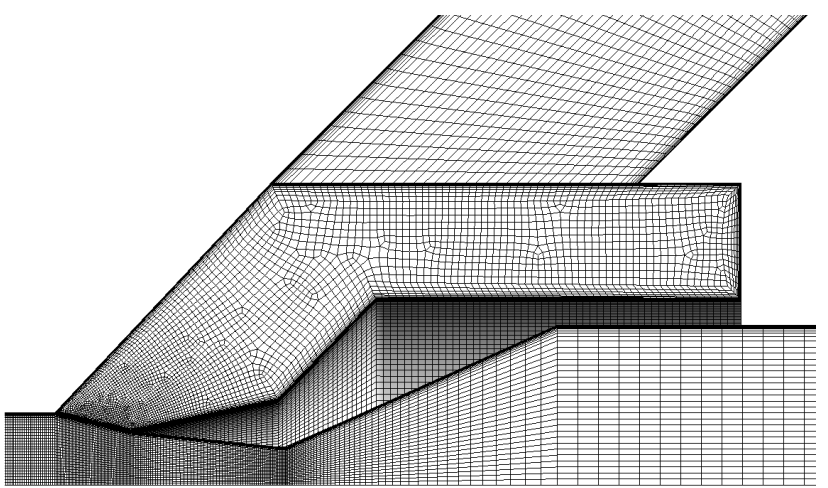

Fig. 7. Detail of the ejector mesh in the vicinity of the primary nozzle.

\section{Analytical approach}

There was used an analytical model for theoretical investigations. The model is currently under development at the Technical University of Liberec, and is based on the 1D model by Chen et al. [10] and the model by Abramovich [11]. The authors of this paper modified both models and combined them together as well as added some new features. The model will be investigated in more details, and introduced in future works. 


\section{Results and discussion}

Fig. 8 provides an approximate illustration all the test runs obtained from Table 1 . As can be seen, two test runs are in the on-design modes with double choking, while the rest of them belong to the off-design modes with single choking.

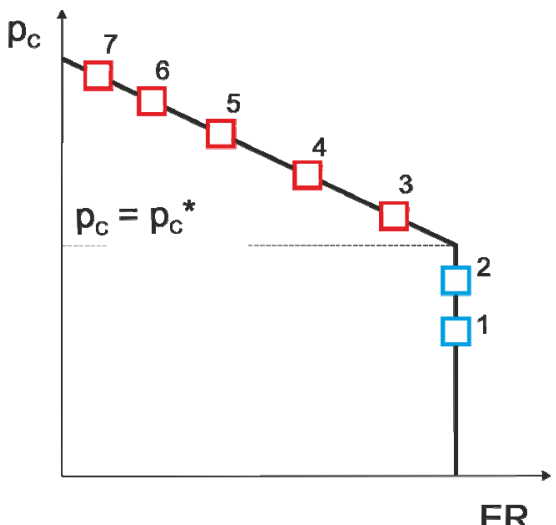

Fig. 8. Approximate representation of the investigated test runs on the performance line of the ejector (boundary conditions on inlets are not constant on this curve).

The courses of the static pressure distribution on the ejector wall for all seven test runs are plotted in figures 9-15. A comparison between both CFD approaches the ideal gas and the real gas with experimental data is obvious from these figures. It can be seen that discrepancies in the static pressure distribution on the ejector wall are low. There are negligible differences for test run no. 1 (Fig. 9). There is obvious a higher discrepancy between the real gas model and the ideal gas model for test run no. 2 (Fig. 10). However, in this case there is a reasonable agreement between the real gas model and the experimental data. As regards the test run no. 3, there is an agreement between the real gas model and the ideal gas model, however, the experimental data is inconsistent with both of these numerical approaches (Fig. 11). The main discrepancy is further expansion of the flow in the mixing chamber for the experiment.

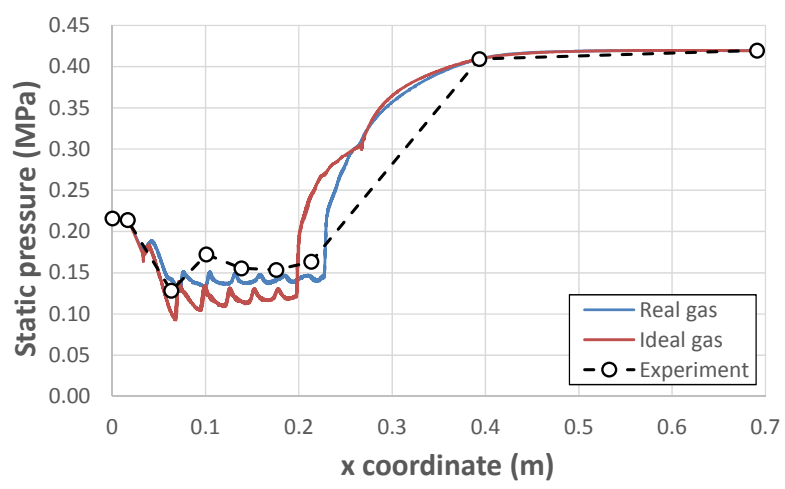

Fig. 9. Static pressure distribution on the ejector wall for the test run no. 1 .

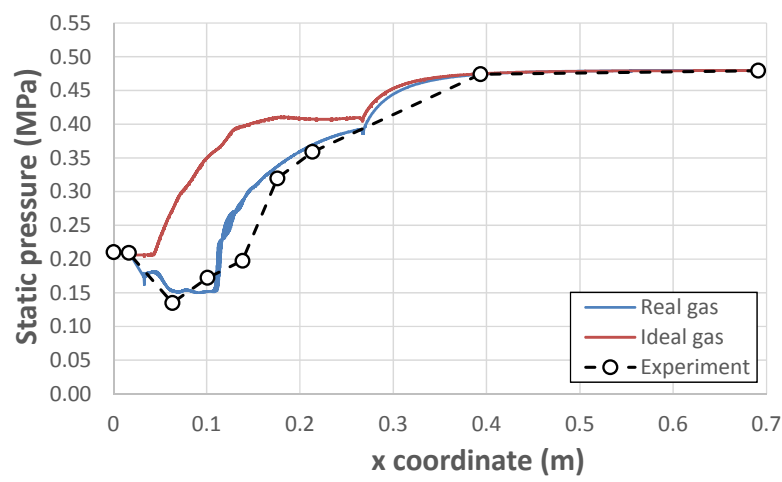

Fig. 10. Static pressure distribution on the ejector wall for the test run no. 2.

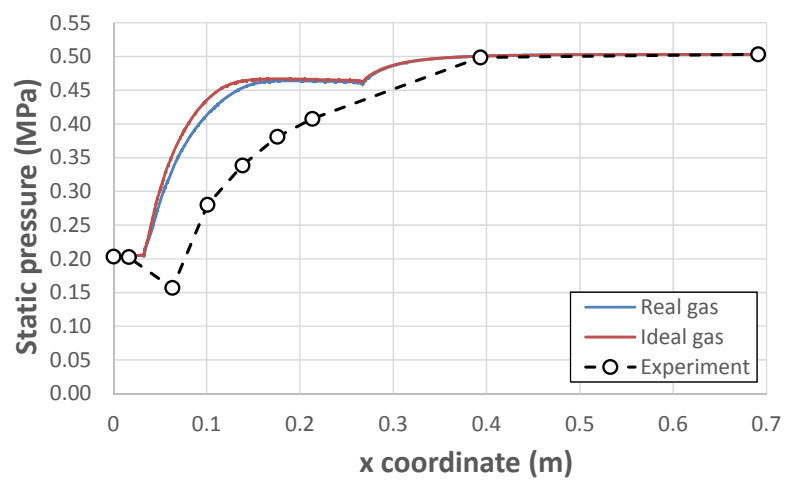

Fig. 11. Static pressure distribution on the ejector wall for the test run no. 3 .

A similar trend can be seen in Fig. 12 for test run no. 4 , apart from the expansion of the flow in the mixing chamber. The test runs no. 5 and 6 are also similar to each other as Fig. 13 and Fig. 14 illustrate, respectively. In both cases, there are only insignificant discrepancies. Obviously, the lowest discrepancies in static pressure courses can be seen for test run no. 7 (Fig. 15). Based on the experimental static pressure courses it can be stated that the ejector is working in the on-design mode for the test run no. 1 and test run no. 2 (Fig. 3 and Fig. 8).

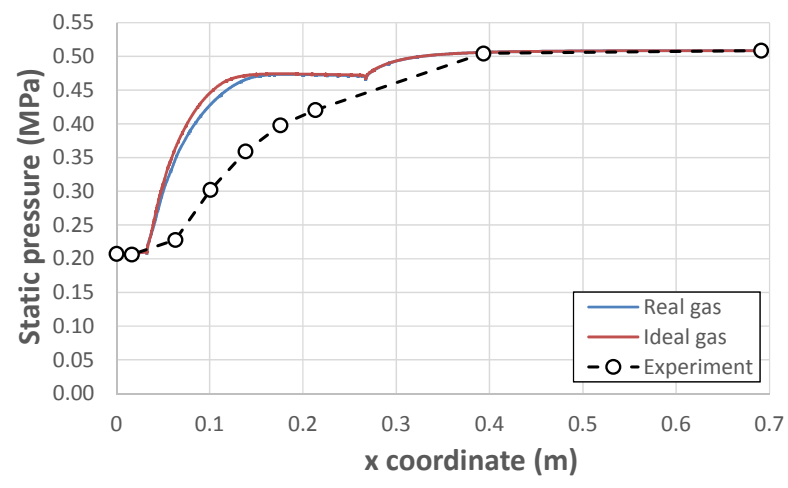

Fig. 12. Static pressure distribution on the ejector wall for the test run no. 4. 


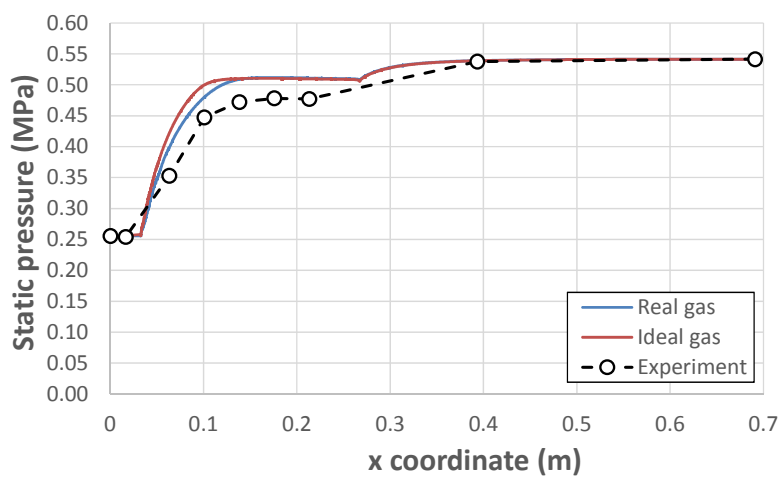

Fig. 13. Static pressure distribution on the ejector wall for the test run no. 5 .

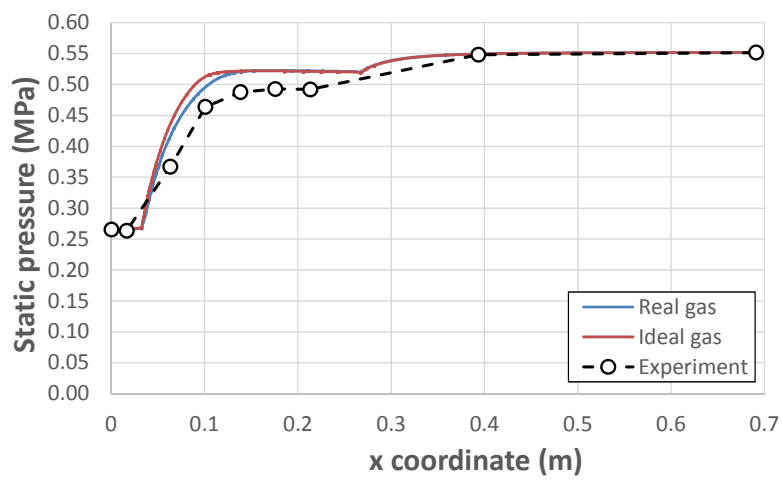

Fig. 14. Static pressure distribution on the ejector wall for the test run no. 6 .

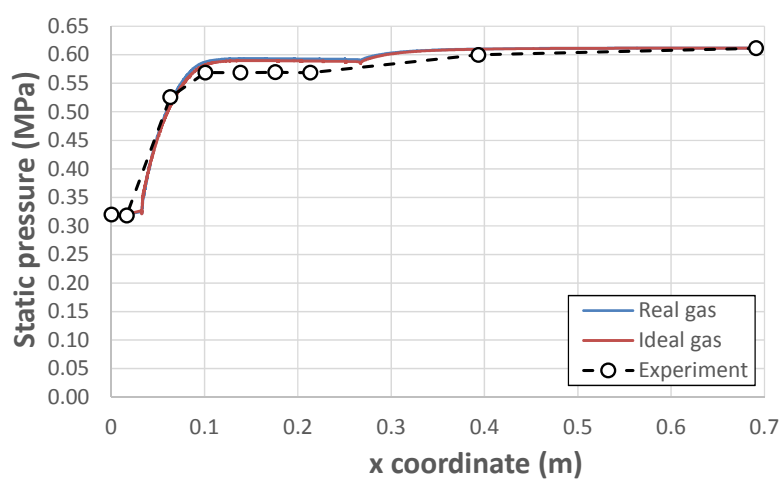

Fig. 15. Static pressure distribution on the ejector wall for the test run no. 7 .

The entrainment ratio comparison for all tested runs is shown in Fig. 16. Significant discrepancies in the entrainment ratio between the experiment and the CFD data based on the real gas model can be observed. Similarly, there are also discrepancies between the experiment and the CFD data based on the ideal gas model.

These discrepancies are lowest for test run no. 1 and test run no. 2. These runs were earlier in the paper identified as the on-design runs, i.e. cases where the secondary flow is choked. Other cases lie beyond $\pm 20 \%$ relative error limit and are not worth mentioning in more detail. It should be noted that there were not obtained any negative values of entrainment ratio from the experiment.

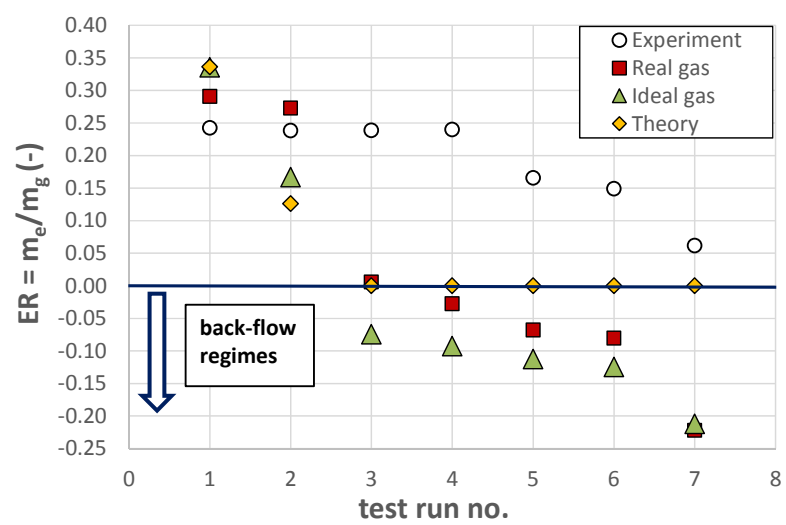

Fig. 16. Entrainment ratio comparison for experiment, real gas (CFD), ideal gas (CFD) and theoretical model.

The highest entrainment ratio obtained from experiment was 0.242 with a corresponding compression ratio of 0.213 (for test run no. 1). On the contrary, the lowest entrainment ratio was found for test run no. 7, ER $=0.062$ and $\mathrm{CR}=0.329$. It can also be seen in Table 2 that the entrainment ratio is inversely proportional to the compression ratio, which is consistent with literature.

Table 2. Values of the entrainment ratio for all test runs.

\begin{tabular}{|c|c|c|c|c|c|}
\hline & CR $(-)$ & $\begin{array}{c}\text { Experiment } \\
\text { ER }(-)\end{array}$ & $\begin{array}{c}\text { Real gas } \\
\text { ER (-) }\end{array}$ & $\begin{array}{c}\text { Ideal gas } \\
\operatorname{ER}(-) \\
\end{array}$ & $\begin{array}{l}\text { Theory } \\
\text { ER (-) }\end{array}$ \\
\hline run no. 1 & 0.213 & 0.242 & 0.291 & 0.336 & 0.336 \\
\hline run no. 2 & 0.277 & 0.238 & 0.273 & 0.167 & 0.126 \\
\hline run no. 3 & 0.310 & 0.239 & 0.006 & -0.075 & 0.000 \\
\hline run no. 4 & 0.315 & 0.240 & -0.028 & -0.093 & 0.000 \\
\hline run no. 5 & 0.309 & 0.166 & -0.068 & -0.113 & 0.000 \\
\hline run no. 6 & 0.312 & 0.149 & -0.080 & -0.125 & 0.000 \\
\hline run no. 7 & 0.329 & 0.062 & -0.222 & -0.212 & 0.000 \\
\hline
\end{tabular}

Apart from the runs no. 1 and 2, the ideal gas model gives negative values of entrainment ratio. On the other hand, the real gas model gives negative values of entrainment ratio for test runs no. 4 to 7 . The entrainment ratio for test run no. 3 is slightly positive, however, it could be argued that the numerical precision plays here a significant role as the value is very close to zero.

As can be seen in Table 3, there are reasonable agreements in the primary mass flow rate for all investigated cases. This can be caused by the fact that the primary flow was choked in all calculated cases. As a matter of fact, it is obvious that both CFD approaches and theory tend to slightly underestimate the mass flow rate of the primary stream. The highest value of the primary mass flow rate was for each test run obtained from the experiment. 
Table 3. Values of the primary (generator) mass flow rate.

\begin{tabular}{ccccc}
\hline $\mathrm{m}_{\mathrm{g}}$ & $\begin{array}{c}\text { Experiment } \\
(\mathrm{kg} / \mathrm{s})\end{array}$ & $\begin{array}{c}\text { Real gas } \\
(\mathrm{kg} / \mathrm{s})\end{array}$ & $\begin{array}{c}\text { Ideal gas } \\
(\mathrm{kg} / \mathrm{s})\end{array}$ & $\begin{array}{c}\text { Theory } \\
(\mathrm{kg} / \mathrm{s})\end{array}$ \\
\hline run no. 1 & 0.486 & 0.461 & 0.460 & 0.461 \\
run no. 2 & 0.493 & 0.478 & 0.465 & 0.463 \\
run no. 3 & 0.488 & 0.462 & 0.461 & 0.459 \\
run no. 4 & 0.483 & 0.458 & 0.458 & 0.457 \\
run no. 5 & 0.488 & 0.460 & 0.462 & 0.463 \\
run no. 6 & 0.489 & 0.464 & 0.464 & 0.464 \\
run no. 7 & 0.495 & 0.470 & 0.470 & 0.473 \\
\hline
\end{tabular}

Table 4. Values of the secondary (evaporator) mass flow rate.

\begin{tabular}{ccccc}
\hline $\mathrm{m}_{\mathrm{e}}$ & $\begin{array}{c}\text { Experiment } \\
(\mathrm{kg} / \mathrm{s})\end{array}$ & $\begin{array}{c}\text { Real gas } \\
(\mathrm{kg} / \mathrm{s})\end{array}$ & $\begin{array}{c}\text { Ideal gas } \\
(\mathrm{kg} / \mathrm{s})\end{array}$ & $\begin{array}{c}\text { Theory } \\
(\mathrm{kg} / \mathrm{s})\end{array}$ \\
\hline run no. 1 & 0.118 & 0.134 & 0.154 & 0.155 \\
run no. 2 & 0.118 & 0.130 & 0.078 & 0.058 \\
run no. 3 & 0.116 & 0.003 & -0.034 & 0.000 \\
run no. 4 & 0.116 & -0.013 & -0.042 & 0.000 \\
run no. 5 & 0.081 & -0.031 & -0.052 & 0.000 \\
run no. 6 & 0.073 & -0.037 & -0.058 & 0.000 \\
run no. 7 & 0.031 & -0.104 & -0.100 & 0.000 \\
\hline
\end{tabular}

Table 4 illustrates results for the secondary mass flow rate. It is obvious that the discrepancies in the entrainment ratio are mainly caused by an improperly computed secondary mass flow rate. In this regard, all used methods for predicting flow in an ejector fail. Moreover, it should be pointed out that the presented analytical model is unable to predict back-flow regimes, i.e. regimes where the secondary mass flow rate has got a negative value. In such cases the analytical model gives a zero secondary mass flow rate.

Probably the key parameter for assessing the quality of the mixing the motive and the entrained flow is the mixing length and the area where the secondary flow reaches its maximal velocity and in some cases (ondesign modes) becomes choked. CFD can help to evaluate that, but it needs to be in a reasonable agreement with experimental data first.

Figures 17 to 20 illustrate the contours of Mach number in the motive nozzle and the mixing chamber for test run no. 1 and 2.

The flow in the ejector during the test run no. 1 is for the ideal gas model and the real gas model obvious from Fig. 17 and Fig. 18, respectively. Evidently, the primary nozzle operates in the over-expanded regime in both cases the ideal and the real gas model, because the jet of the primary stream is slightly converged toward the ejector centre and a complex pattern of shocks and reflections is evolved in the mixing chamber. As a result, the choking of the secondary flow occurs further downstream in comparison to the under-expanded jet. Additionally, the ideal gas model tends to predict higher Mach numbers in the entire ejector. As regards the position of the closing shock wave, the real gas model predicts the shock wave further downstream compared to the ideal gas model. Nevertheless, the choking of the secondary stream occurs approximately at the same distance downstream the motive nozzle, and forms almost the same fictive throat for both the ideal and real gas model. This could be the reason for the low discrepancy in the secondary mass flow rates between the ideal and real gas model.

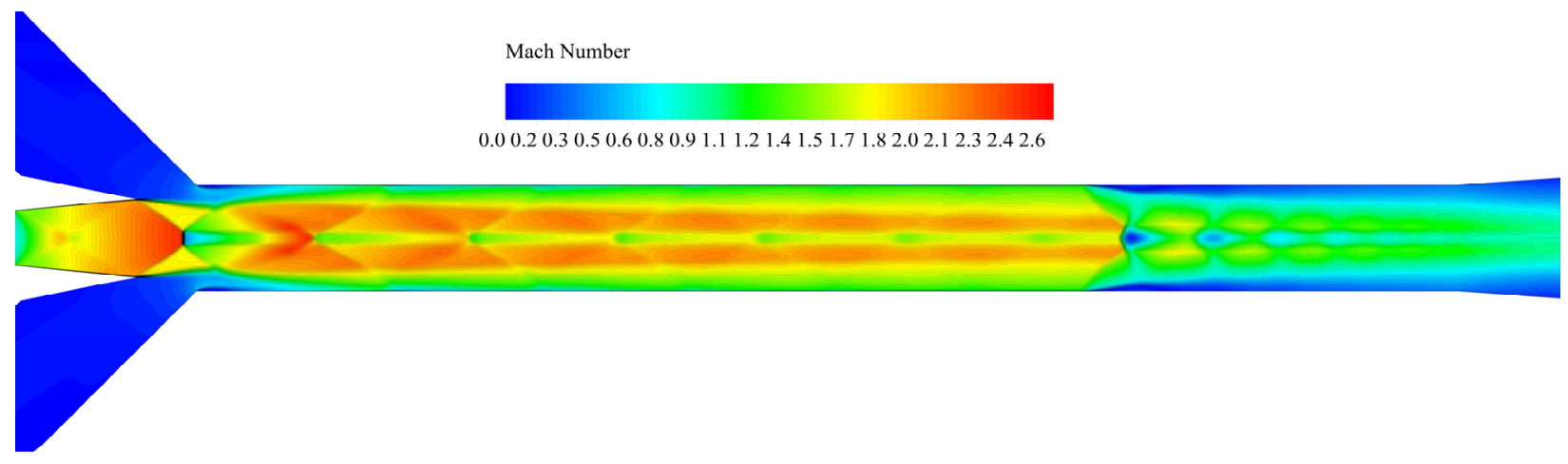

Fig. 17. Mach number contours for test run no. 1 and the ideal gas model; $E R=0.336, C R=0.213$.

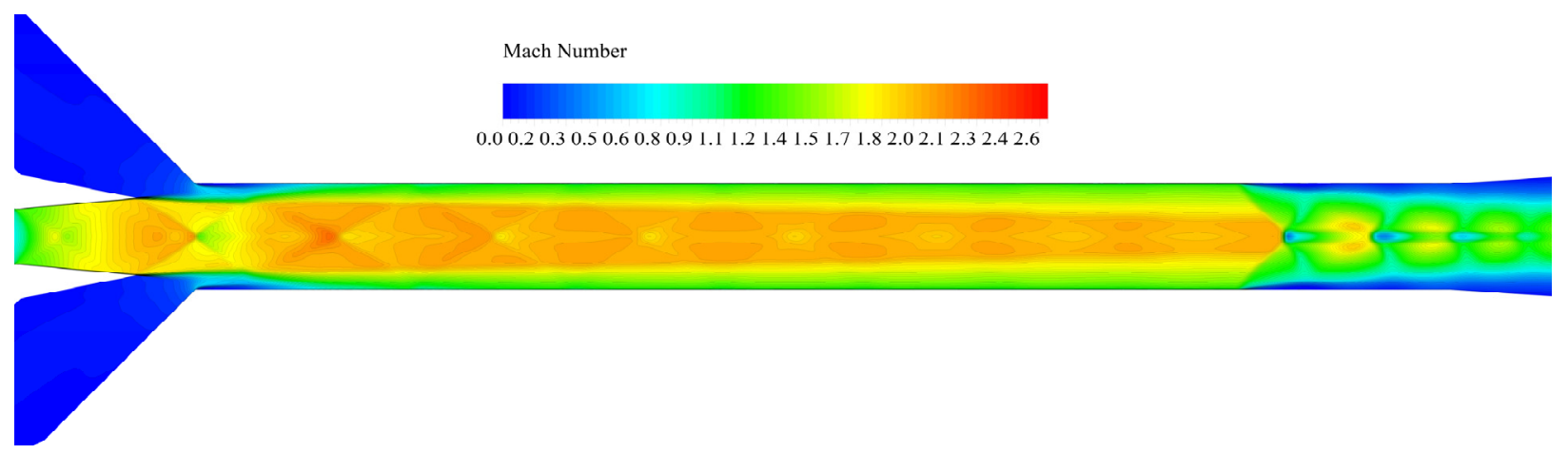

Fig. 18. Mach number contours for test run no. 1 and the real gas model; $E R=0.291, C R=0.213$. 


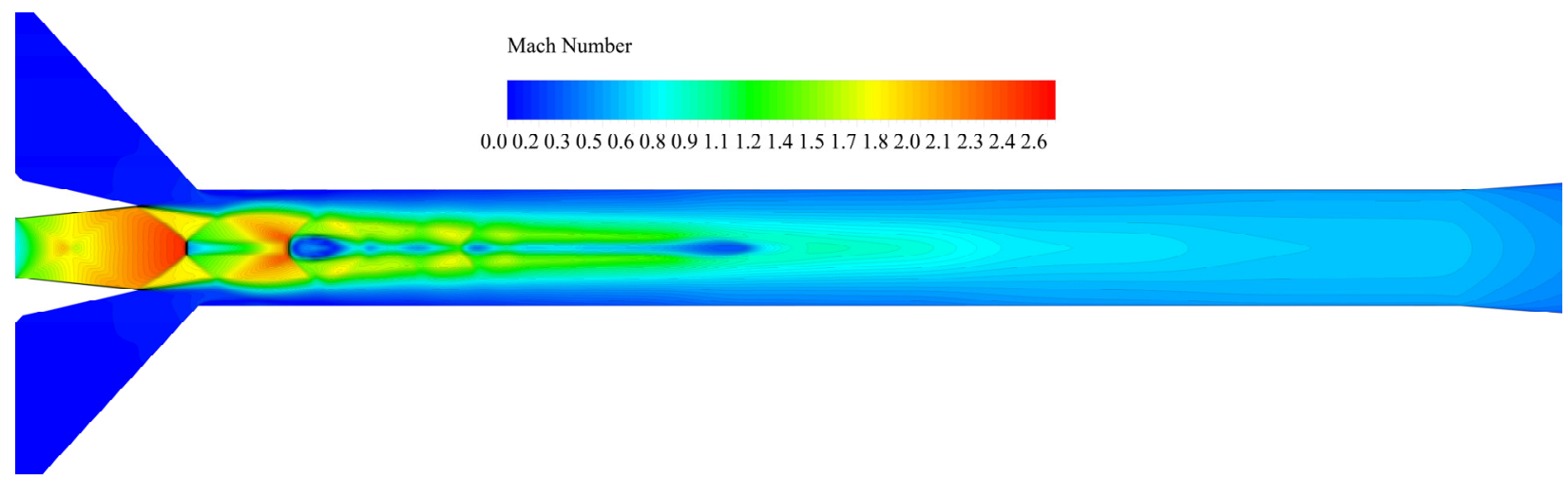

Fig. 19. Mach number contours for test run no. 2 and the ideal gas model; $E R=0.167, C R=0.277$.

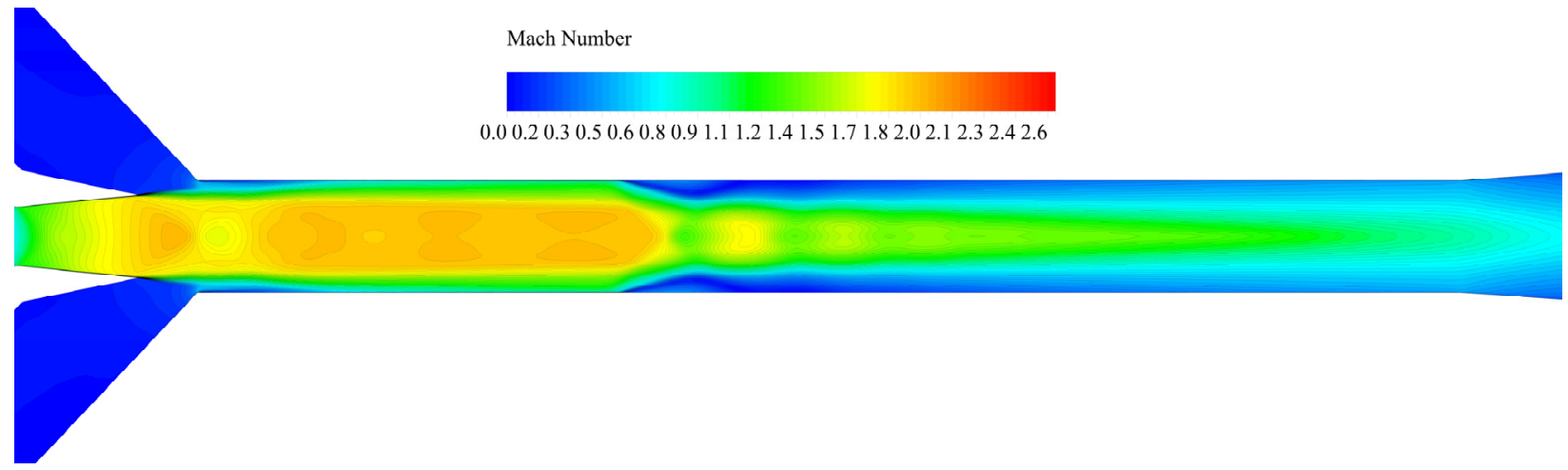

Fig. 20. Mach number contours for test run no. 2 and the real gas model; $E R=0.273, C R=0.277$.

Nevertheless, in both cases is observed the growth of boundary layer until the closing shock wave appears. Moreover, a boundary layer separation is provoked right behind the closing shock wave.

Fig. 19 and Fig. 20 give an illustration of the flow in the ejector during the test run no. 2 for the ideal gas model and the real gas model, respectively. It is observed that the flow patterns are completely different. Since the calculated secondary mass flow rate for the real gas model is closer to the experimental data, it can be assumed that for the given conditions the ideal gas model fails and probably cannot be used for calculations. The secondary mass flow rate for the ideal gas is smaller than for the real gas (Table 4). This is probably due to the fact that the secondary flow is not choked in the former case.

Obviously, in the case with the ideal gas, the ejector is able to entrain only negligible amount of the secondary fluid. For the case with the real gas, the secondary flow becomes choked slightly further compared to the test run no. 1. On the contrary, the closing shock wave is weaker and occurs more upstream for this case. As a result, a strong boundary layer separation can be seen in the mixing chamber section (Fig. 20). In conclusion, it is obvious that further tests are required to obtain more accurate results.

\section{Summary and conclusion}

This paper concentrates on the validation of a CFD tool for a supersonic ejector working with R-1234ze(E) as a low global warming potential refrigerant. The selection of this fluid was on the basis of the analysis of the working fluids for ejector system with respect to Regulation of the European Parliament and the EU Council No. 517/2014 [5].

The CFD results obtained on simplified 3D models have been presented for both the ideal and real gas. The comparison with the experimental data shows significant discrepancies in mass flow rates, especially in the offdesign region. This could be caused by simplified numerical models or more likely by inability of the physical models of the solver to capture all the relevant phenomena that occur within the mixing chamber and diffuser. On the other hand, the comparison of static pressure distributions shows reasonable discrepancies. Furthermore, the contours of Mach number have shown several common phenomena in ejectors: a motive nozzle working regime, a region of the choking of the secondary flow, a closing shock wave, and a boundary layer separation.

The highest entrainment ratio during experiments was 0.242 (test run no. 1). Nevertheless, this test run gives the lowest compression ratio of 0.213 . On the other hand, the lowest entrainment ratio was 0.062 (test run no. 7) and corresponding compression ratio was 0.329 . Based on the experimental data, any ejector test run has not been proved to be working in the back-flow mode. 
On the contrary, the calculation of the flow by means of the real gas approach gives the back-flow mode for four test runs; and the ideal gas approach even five out of seven test runs.

The primary mass flow rates were in a good agreement for all tested runs. This was probably caused by the fact that the primary flow was choked in all calculated cases. However, it is worth mentioning that both CFD approaches and theory tend to slightly underestimate the mass flow rate of the primary flow. The highest value of the primary mass flow rate was for each test run obtained from the experiment.

It seems that most of the difficulties during the calculation of the flow in ejectors are caused by the incorrectly computed secondary mass flow rate. It is generally well-known fact that prediction of the secondary mass flow rate is a challenging task in many branches.

It appears that there is still need for a deeper investigation on ejectors in conjunction with refrigeration applications as there are significant discrepancies in mass flow rates between CFD and experimental data, especially the secondary mass flow rate in the off-design mode. Only two tested runs out of seven seem to be in a sufficient agreement with the experimental data. It is believed that it cannot be a coincidence, however, there needs to be an extensive validation performed in order to be able to predict the flow in ejectors working with common refrigerants more correctly.

Validation test runs over the entire range of operating conditions are still required. It should be a motivation for further research to prove the ability of CFD to model different operating regimes. Furthermore, a more comprehensive analysis of the experimental data and CFD is desired for better understanding the flow processes that occur within the ejector mixing chamber and diffuser. In addition, it has been also shown that the presented analytical model is unable to predict back-flow modes, i.e. modes with a negative secondary mass flow rate, and in such cases gives a zero secondary mass flow rate regardless the magnitude of the negative flow rate. It is worth mentioning that the model is still in development since a deeper understanding of the processes in ejectors is highly desirable. Finally, further tests will be required to obtain more accurate results.

\section{Acknowledgement}

This publication was written at the Technical University of Liberec as part of the Czech-Polish project "Research of processes in supersonic ejectors with isobutane" no. 7AMB16PL011 and as part of the project "Experimental and numerical investigation in applied fluid mechanics and energy devices, no. 21124" with the support of the Specific University Research Grant, as provided by the Ministry of Education, Youth and Sports of the Czech Republic in the year 2017

\section{References}

1. K. Smierciew, D. Butrymowicz, J. Gagan, V. Dvorak. Int. Conf. Compressors Cool. 9, (2017).

2. J.H. Keenan, E.P. Neumann. J. Appl. Mech. 64, 7581 (1942).

3. D. W. Sun, I. W. Eames. J. Ins. Energy, 68, 6579, (1995)

4. J. Kracik, V. Dvorak. Exp. Fluid Mech. 92, (2015).

5. Smierciew, K., Gagan, J., Butrymowicz, D., Łukaszuk, M. \& Kubiczek. Appl. Therm. Eng. 110, 115-125 (2017).

6. E.W. Lemmon, M.L. Huber, M.O. McLinden. Natl Std. Ref. Data Series. 9.1, (2013)

7. M. Thol, E.W. Lemmon, Int. J. of Thermophys. 37, (2016)

8. J. Koláŕ, V. Dvořák. Int. J. Mech. Mechatronics Eng. 5, 1715-1719 (2011).

9. ANSYS. ANSYS FLUENT User's Guide. 15317, 2498 (2011).

10. W. Chen, M. Liu, D. Chong, J. Yan, A. B. Little. Int. J. Refrig. 36, 1750-1761 (2013).

11. G. N. Abramovich. Applied Gas Dynamics. Third Edition. (Defense Technical Information Center, 1973). at https://books.google.cz/books?id=LISOAAACAAJ 